\title{
Development of Draping Learning Media Through Dress Form in Determining the Pear Body Shape Compensation Ratio on Custom Skirts \\ Vivi Radiona S.P. and Esty Nurbaity A.
}

Vocational Education Program, Fashion Design Studies program, State University of Jakarta, Jakarta, Indonesia

\section{Abstract}

Skirts are one of the three fashion groups that have been around for a long time. The problem that is often faced by women with Pear body shape (pointy triangle up) when wearing a skirt is the side of the skirt that eavesdrops, the side rises up, the pelvic line rises, and the stomach part shrinks. The big difference between the size of the waist circumference and the pelvic circumference affects the quality of clothing. The pattern compensation ratio is a ratio determined to reduce the size of the clothing pattern. The

Corresponding Author: Esty Nurbaity A. estynurbaity@gmail.com

Received: 11 January 2019 Accepted: 14 February 2019 Published: 25 March 2019

Publishing services provided by Knowledge E

(c) Vivi Radiona S.P. and Esty Nurbaity A.. This article is distributed under the terms of the Creative Commons

Attribution License, which permits unrestricted use and redistribution provided that the original author and source are credited.

Selection and Peer-review under the responsibility of the 3rd ICTVET 2018 Conference Committee. compensation ratio on the pattern can be used on a custom skirt that is developed to be wider toward the right and left to make the ends of the skirt evenly. The pattern compensation ratio can be used on standard or fully developed skirts. The result of applying the pattern compensation ratio to the custom skirt depends on the type of material used. The Application Compensation ratio gives good results on materials with light, thin, and translucent properties, but materials with slightly heavy, shiny, and rather thick properties still need to be corrected in the pattern compensation ratio used. Although it is able to reduce the length of the fiber, it has not been able to produce a regular skirt that is parallel to the floor.

Keywords: compensation ratio, learning media, skirt

\section{Introduction}

Draping is one of the fashion making systems in addition to the construction system, the advantages of the draping pattern system is that the application of the design can be directly realized using dress form media. By using dress form media, we can immediately see the quality of the results based on the level of suitability of the design [1].

Women's body shapes are categorized into four, namely: Body Shape Hourglass (time glass), Rectangular Body Shape (rectangle or straight), Apple Body Shape (pointed triangle down), Pear Body Shape (pointed triangle upwards) [2]. The body shape of 
Pear Body Shape (pointy triangle upwards) has a characteristic size of the waist and hip difference that is quite far away, with a body shape like this, women usually have problems using skirts. The problem that is often faced by women with Pear Body Shape body shape (pointy triangle up) when wearing a skirt is the side of the skirt that eavesdrops, the side rises up, the pelvic line rises and the stomach part shrinks. The more difference between the size of the waist and the pelvis, will cause the quality of clothes that are not good.

Development of geometric methods of measuring dimensional changes by calculating the fabric compensation ratio in the direction of attack by applying the fabric draping ratio, a theoretical method for making bias-cut patterns using gravitational forces and the fall properties of fabrics applied to custom skirts. Draping technique is very possible to form fashion uniquely and can be worn on the human body.

\section{Result}

The results of applying pattern compensation ratios to materials with mild, thin and translucent properties differ from those with slightly heavy, shiny and rather thick properties, this is influenced by differences in the types of weaving available. The light material uses plain weaving and thick material using satin woven. Satin weaving is known as the most easily stretched weaving while plain weaving is the strongest weaving among the three basic weaves.

Making satin yarn with a low twist causes less elasticity and weaving using jump numbers to make the fabric easier to stretch. This is caused by the braid points produced by a little satin woven. While the manufacture of plain woven yarn uses a high twist so that it produces good elasticity. The number of braid points produced by plain weaving also produces a stronger fabric [3].

The pattern compensation ratio is calculated using a formula:

$$
\text { Pattern Compensation }(\%)=\frac{100}{100+\text { rasio regangan }} \times 100
$$

\section{Calculate the Pattern Compensation Ratio}

\section{Average Angle of Change}

\section{Changes in Dimensions in Cloth Serong}

The value of the elongated direction voltage $(\mathrm{Lr}) \times 100$ 


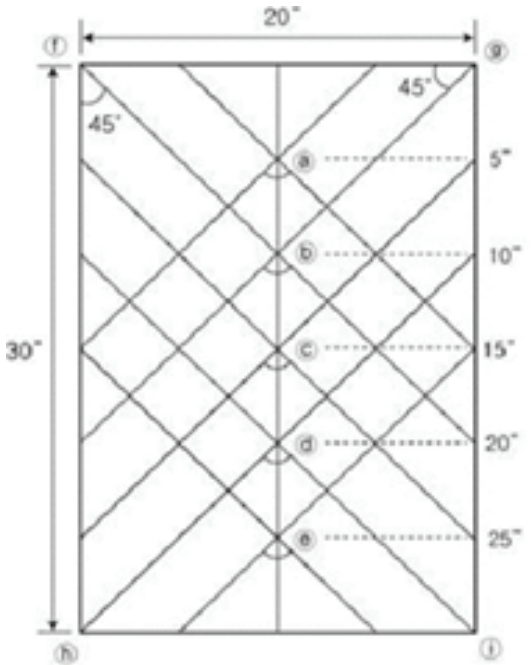

(a) Angle measuring points

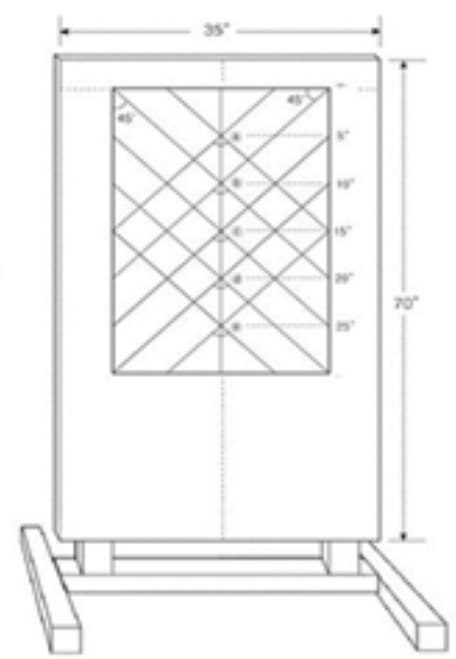

(b) Placement of the specimen on the angle measuring stand Figure 1

Where $L^{\prime}=$ long after hanging $=2 \times \cos \theta / 2$

$$
\begin{aligned}
L & =2 \times \cos 2 \ldots \ldots \ldots \ldots \text { where }=90^{\circ} \\
& =2 \times \cos 45 \\
& =2 \times 0.70 \\
& =1.41 \\
& =- \\
L^{\prime} & =2 \times \cos 2 \ldots \ldots \ldots \text { where }=85.8 \\
& =2 \times \cos 42.9 \\
& =2 \times 0.73 \\
& =1.46 \\
L r & =\frac{L^{\prime}-L}{L} \times 100 \\
& =1.46-1.41 \times 100 \\
& 1.41 \\
& =3.9
\end{aligned}
$$




\section{Discussion}

The pattern compensation ratio can be used on custom skirts to get the final edge of a flat skirt. Using a pattern compensation ratio makes making a more practical skirt more practical than determining the length of the side with the center length of the skirt face first and then cutting the bottom edge to smooth the suede skirt. The pattern compensation ratio can be used on standard or custom skirts that have undergone widening on both sides, but the results of applying pattern compensation ratios to custom skirts depend on the criteria of the material used. For plain, light, thin and translucent materials, the compensation ratio can be applied properly and give very satisfying results, namely flat skirts that are flat or parallel to the floor. However for satin-woven material, it is slightly heavy, shiny and somewhat thick. there is still a need to make corrections to the pattern compensation ratio used, because even though it is able to reduce the length of the fiber, it has not been able to produce a smooth skirt that is parallel to the floor.

\section{Conclusion}

Making the bottom edge of the skirt (new pattern line) after applying the pattern compensation ratio is done by dividing the known pattern and angle compensation ratio. If the known angle is $X$ and the pattern compensation ratio is $Y$, the new point that will be formed is at angle 22. Suppose that at an angle of 450 the known pattern compensation ratio is 2 , then at an angle of 22.50 the compensation ratio of the applied pattern is $1 \mathrm{~cm}$ and at an angle 11.50 the enough to form a gentle curved line.

\section{Acknowledgement}

The authors would like to thank their colleagues for their contribution and support to the research. They are also thankful to all the reviewers who gave their valuable inputs to the manuscript and helped in completing the paper.

\section{Conflict of Interest}

The authors have no conflict of interest to declare. 


\section{References}

[1] Chan Ho Park and Jongsuk Chun, Development of the Bias-Cut Dress Pattern Making Method by Applying Fabric Draping Ratio. https://www.researchgate.net/ publication/267776709

[2] Amstrong, Helen Joseph. (1987). Pattern Making For Fashion Design. New York: Arper \& Row Publisher.

[3] Hillhouse, Marion, \& Evelyn A Mansfield. (1948). Dress Design Draping and Flat Pattern Making. United States of America: The Riverside Press Cambridge.

[4] G. Holman, Bias - cut dressmaking. https://www.researchgate.net/publication/ 267776709

[5] http://www.readorrefer.in/article/Identification-of-Grain-in-designing-of-woventextiles-and-garment-designing_1875/, tanggal 23 January, pukul 13.00. 